\title{
CAMUFLAGEM E TRANSPARÊNCIA
}

\author{
CAMOUFLAGE AND TRANSPARENCY \\ CAMUFLAJE Y TRANSPARENCIA
}

\author{
Maria de Fátima de A. Silveira' ${ }^{1}$ \\ Vera Sobral ${ }^{2}$ \\ Camen Sylvia de A. Junqueira ${ }^{3}$
}

RESUMO: o ensaio estabelece, a partir da compreensão de ELIADE, analogias entre alguns símbolos universais e os rituais de morte desenvolvidos pela Enfermagem, desnudando a camuflagem ali existente e apontando sua transparência como forma de enriquecer a prática profissional, beneficiando cuidadora(e)s e sujeitos do cuidado.

PALAVRAS-CHAVE: simbolismo, Enfermagem, rituais de morte

\section{ADENTRANDO AO TEMA ...}

Em artigo que integra uma edição especial do livro Notes on nursing, de Florence, onde várias autoras comentam a obra a partir de um aspecto, Styles (1992) afirma que Nightingale é o símbolo duradouro da Enfermagem. Figura endeusada, idealizada, execrada ou retomada recentemente como política, reformista, foi a feminista possivel à época vitoriana, conforme Miranda (1998), tendo sido a primeira mulher a receber a Ordem do Mérito de seu país. Seu nome está incluído entre os humanistas que mudaram o mundo.

No Brasil, entretanto, Florence é reconhecida quase sempre apenas nas aulas de História da Enfermagem, tendo se tornado um mito fundante distante da prática, possivelmente porque fala a uma realidade inglesa, não atualizada em nenhum rito, a não ser na data que marca as solenidades da Semana da Enfermagem, que se inicia em 12 de maio, data de seu nascimento.

Ao aproximar essa observação da compreensão de Eliade ${ }^{4}(1996)$, é possivel entender que isso aconteça porque os símbolos ligados a fatos culturais e, portanto, históricos específicos, são bem menos representados que os simbolos de estrutura cósmica ou que se relacionem com a condição humana, que, para o autor, constituem arquétipos e configuram matrizes universais.

A entrada de Florence no cenário da Enfermagem fez-se pela porta do hospital inglês, enquanto a Enfermagem brasileira fez um percurso inicial pelas vias da saúde pública, atendendo a imperativos econômicos específicos daqui e, portanto, contendo em seu âmbito simbólico outros elementos que não os culturais da Inglaterra de 1845.

\section{A COMPREENSÃO DE SIMBOLISMO EM ELIADE}

O símbolo, o mito e a imagem pertencem à substância da vida espiritual e, embora se

\footnotetext{
'Enfermeira. Profa. do Departamento de Enfermagem da UEP. Doutoranda EEUSP.

2 Enfermeira. Profa. da EEAACIUFF. Doutora em Enfermagem.

${ }^{3}$ Profa. Titular do Departamento de Antropologia , Faculdade de Ciências Sociais - PUCSP.

4 Mircea Eliade (1907-1986), romeno, filósofo, historiador das religiöes, poeta e romancista.
} Autor, entre outras obras, de Tratado de História das Religiões (1998), O sagrado e o profano (1999), Aspectos do Mito (1989). 
possa camuflá-los, mutilá-los, degradá-los, eles não podem jamais ser extirpados, pois são consubstanciais ao ser humano, precedendo a linguagem e a razăo discursiva; não é, portanto, uma área exclusiva das crianças, poetas e desequilibrados, afirma Eliade ${ }^{4}$ (1991; 1998).

$\mathrm{Na}$ visão desse autor, o símbolo revela alguns aspectos da realidade - os mais profundos - que não são acessíveis a qualquer outro meio de conhecimento. "As imagens, os símbolos e os mitos não são criações irresponsáveis da psique; elas respondem a uma necessidade e preenchem uma função: revelar as mais secretas modalidades do ser".

A extirpação dos mitos ${ }^{5}$ e símbolos é ilusória e a imaginação, porção essencial e imprescritivel do homem, está imersa em pleno simbolismo e vive dos mitos e teologias arcaicas. Por isso, "as imagens têm o poder e a missão de mostrar tudo o que permanece refratário ao conceito".

O homem mais "realista" ou "a mais pálida das existências" está repleta de símbolos, vive de imagens. O teatro, o cinema (a fábrica de sonhos), a música, a poesia, têm no contexto atual a função de realimentar os simbolos e as imagens.

O símbolo cumpre sua função ao transmitir uma mensagem, mesmo quando sua significação escapa à consciência, mesmo quando degradado, modificado, camuflado, porque "dirige-se ao ser humano integral e năo apenas à sua inteligência" (Eliade, 1991).

A principal caracteristica do símbolo é a simultaneidade de sentidos que ele revela, pois foram forjados em um contexto de diversidade e riqueza tais que apresentam uma valência universal capaz de fazer com que sejam absorvidos e compreendidos em qualquer cultura.

Os simbolos e as imagens têm valências universais porque são "aberturas" para um mundo trans-histórico, conservando as culturas "abertas". Ao mesmo tempo, apesar de serem produtos do inconsciente, são depurados no processo histórico e cultural em que estejam inseridos. A história pode acumular novas significaçōes à estrutura original do simbolismo, mas não a destrói.

O simbolismo integra e unifica, mas sem fusionar, o maior número possivel de objetos, de situações ou modalidades. Ao tornarem-se simbolos, os objetos "anulam seus limites concretos, deixam de ser fragmentos isolados para se integrar num sistema, ou melhor, eles encarnam em si próprios, a despeito de sua precariedade e do seu caráter fragmentário, todo 0 sistema em questão" (Eliade, 1991; 1998).

Diante dessas considerações, o autor admite ser legítimo falar de uma "lógica dos símbolos" , pois qualquer que seja a sua natureza e o plano em que se manifestem, são sempre coerentes e sistemáticos.

\section{SIMBOLISMO NA PRÁTICA DE ENFERMAGEM: "ELES" AINDA ESTÃO AQUI}

Um símbolo que Florence utilizou e que deriva de uma matriz universal (a Luz) "migrou" até nós e hoje permanece presente em nosso imaginário, ainda que não nos apercebamos do seu valor simbólico maior: a lâmpada.

Certamente Florence utilizou muitos instrumentos em sua prática, mas o que se destacou e aparece com freqüência na Enfermagem brasileira é a lâmpada, que é o símbolo da $A B E n$ (Associaçăo Brasileira de Enfermagem), e encontra-se quase sempre nos convites e placas de formatura das turmas concluintes dos cursos superiores e de auxiliares e técnicos em enfermagem.

Ao estudar várias experiências misticas, Eliade(1991) aponta que a luz é sempre um

${ }^{5}$ Mito, em ELIADE (1999, 1989), é uma história sagrada, cujos personagens são os deuses: narra um acontecimento primordial que teve lugar no começo do tempo e tem como função dominante "fixar" modelos exemplares de todos os ritos para orientar o ser humano em todas as suas atividades significativas. 
tema importante na experiência religiosa e, embora disponha de uma variedade de morfologias, , há um denominador comum, qual seja, a saída de um Universo profano e da situação histórica específica e a projeção num Universo qualitativamente diferente, transcendente e sagrado - a superação da condição humana.

Eliade (1991) adverte que a estrutura desse Universo transcendente e sagrado varia de cultura e de religião. Para o autor, a significação da Luz sobrenatural é dada à alma daquele que a experimenta, mas tal significado "só chega à consciência integrada numa ideologia preexistente", o que constitui, de certa maneira, um paradoxo, pois embora seja uma descoberta pessoal, "cada um descobre aquilo que estava espiritual e culturalmente preparado para descobrir".

A que morfologia diz respeito a lâmpada de Florence e a significação da mesma enquanto simbolo para as enfermeiras brasileiras? Um estudo mais acurado pode desvendar o que da matriz universal está presente em tal simbolismo, mas tornaria o presente ensaio bastante longo.

Entre tantos que possam ser identificados, dois exemplos de simbolismos na prática de enfermagem , a partir da leitura de Eliade, estão presentes nos rituais relativos à morte desenvolvidos pela equipe de enfermagem que, embora de tảo deformados e empobrecidos, são quase irreconheciveis como arquétipos, confundindo-se na técnica pela técnica.

Ao estabelecer a importância da Lua para o pensamento arcaico-religioso, Eliade (1998) afirma que, para tal compreensão, a Lua é o primeiro morto, pois durante três dias o céu fica escuro. Mas, como a Lua renasce na quarta noite, os mortos também adquirem uma nova modalidade de existência. Assim, a morte não é uma existência mas uma modificação provisória do nivel de existência.

Esta "vida na morte" é validada e valorizada pela "história" da Lua, por onde os mortos transitam após passar pela terra e voltam em seguida para a regeneraçăo e obtenção de forças necessárias a uma nova existência. Dai que muitas crenças designam a Lua como a pátria dos mortos, enquanto, para outros povos, após essa passagem, os mortos se dirigem ao Sol. Nessa concepção, "toda a geografia mítica da morte foi projetada em planos celestes: Lua, Sol, Via-Láctea" (Eliade, 1998).

A Enfermagem também usa uma geografia para a morte, de cimento e concreto: o necrotério. Para lá são levados os mortos antes de ser levados pelos seus familiares. É possivel que reservar um lugar especifico para o momento após a morte deve-se não apenas à necessidade de separar o morto de outros pacientes, pois muitos podem falecer em apartamentos individuais ou centros cirúrgicos, por exemplo, onde não há outros pacientes ao lado. Mas essa cartografia da morte no espaço hospitalar é uma "pálida imagem" de que o simbolismo permanece no imaginário, ainda que empobrecido e mutilado, como o exemplo citado.

Semelhantemente ao "espaço lunar", o necrotério é uma etapa no decurso de um processo que pressupõe outras etapas (Sol, Via-Láctea, "círculo supremo" - velório em casa ou em igrejas, ritos funerários, sepultamento). A lua é fria e o necrotério hospitalar também (tem algum que não é); a lua aparece no fim do dia e o necrotério se localiza - via de regra - no fim do hospital. Assim, ao morrer, o paciente deixa de receber os cuidados (quentes) através do toque da equipe de enfermagem, sendo transferido para um lugar frio, e será , a exemplo da concepção que imagina a viagem dos mortos pelo sol, "aquecido" agora pelo calor dos familiares e amigos.

Outra identificação de ritual nos cuidados com o corpo após a morte, encontramos ao estudar o "simbolismo dos nós" em Eliade (1996), embora o tema do "nós" esteja presente na conformação de metáforas sobre a prática profissional das enfermeiras e o cuidado, a exemplo do trabalho de Silveira et al. (1998), "os nós que atam a autonomia da enfermeira", quando são apontados os entraves e perspectivas na relação enfermagem $\times$ autonomia; e o plástico texto de Figueiredo e Carvalho (1998), "Na teia do cuidar os delicados 'nós' do cuidado", onde as autoras partem da metáfora "teia de aranha", identificando os fios ao cuidar, a aranha à 
enfermeira, e os nós da teia às dificuldades do processo de cuidar .

Para Eliade (1996), o mais invencível dos Deuses, o Soberano Terrível das mitologias indo-européias, mas também presente em outras concepções religiosas, não combate com os meios militares, mas tem o monopólio da arma da magia, freqüentemente representada na forma de amarra, nó, laço, concretos ou figurados. Os elementos do complexo mágico-religioso de todos os mitos, ritos e superstições centrados no tema do "amarrar" são a doença e a morte.

Eliade (1996) traça um paralelo etnográfico entre os fatos indo-europeus e de outros grupos, concluindo que é possível classificar os fatos mais importantes sob duas rubricas: as amarras mágicas utilizadas contra os adversários humanos e sua operação inversa do "corte das amarras" realizadas por esses inimigos; e os nós e as amarras benéficas, enquanto meios de defesa contra as doenças, os feitiços, os demônios e a morte; os nós provocam a doença e também a afastam ou curam o doente; trazem a morte e também a afastam.

Resulta daí um simbolismo extremamente denso que exprime duas coisas essenciais: "por um lado, que, no Cosmos como na vida humana, tudo está ligado através de uma textura invisivel; por outro, que certas divindades são mestras desses 'fios' que, em última análise, constituem uma vasta 'amarração' cósmica" (Eliade, 1996).

No que consiste, afinal, o "pacote" que a equipe de enfermagem realiza ao concluir os cuidados com o corpo após a morte?

Ao descrever a técnica de preparo do corpo após a morte, Mamede et al. (1984) expõem as "amarrações" a serem realizadas durante o procedimento. Evidentemente, algumas etapas destinam-se a manter o corpo "arrumado" para o velório, como por exemplo: unir as mãos sobre a cintura e amarrá-las com atadura de crepe; juntar os pés e amarrar com atadura de crepe; amarrar uma etiqueta com cordonê nos tornozelos, se o corpo for para a necrópsia; dobrar o lençol em envelope sobre o corpo, fixando com alfinetes (atualmente, essa etapa da 'amarração' é feita com fita crepe).

Apesar de não descrever o processo como tal tarefa deve ser desenvolvida, Atkinson (1989) ilustra com uma fotografia como deverá ficar o corpo morto preparado pela Enfermagem. É claro, então, que o corpo morto se encontra "literalmente" acorrentado.

Tal ato se realiza mesmo sabendo-se que o morto não irá ser entregue a seus familiares daquela forma, pois é comum, entre nós, que o morto seja enterrado com uma "mortalha" ou alguma roupa escolhida pela família para esse fim. Algumas vezes, o "pacote" não dura mais que minutos até a chegada da família. Mesmo assim é realizado, porque configura "uma mescla de ritual com seguimento de uma rotina e rigor técnico" (Ribeiro et al., 1998).

Pela ótica eliadeana, essa atividade pode significar, para a equipe de enfermagem que a realiza, que a grande e definitiva "amarra" - a morte - foi feita. Entretanto, como um simbolismo tão rico permite não apenas uma interpretação, é possível que tal conduta signifique que as enfermeiras e suas equipes sejam representantes daquelas "divindades mestras" de fios, transubstanciados a partir de esparadrapos e fitas adesivas, ligando ao Cosmos aquela vida humana, realizando a "amarração cósmica".

A preocupação de "encaminhar" o morto ao encontro dos seus antepassados foi identificada por Reis (1995), quando estudou os rituais de morte no Brasil do século XIX. Para o autor, a origem dos ritos fúnebres está na fusão da cultura funerária de Portugal e da África: "tanto os africanos como os portugueses eram minuciosos no cuidado com os mortos, banhandoos, cortando o cabelo, a barba e as unhas, vestindo-os com as melhores roupas ou com mortalhas ritualmente significativas". Segundo o autor, esses cuidados eram da maior importância, "uma das garantias de que a alma não ficaria por aí penando (...) os nagôs acreditavam que a falta dessa cerimônia impedia o morto de encontrar seus ancestrais, tornando-se um espírito errante, um isekú".

Uma das orações comuns no interior do Nordeste, recitada no momento da morte, 
expressa , também, o rico simbolismo dos "nós" no sincretismo religioso católico. Por três vezes consecutivas chama-se o nome do agonizante, orientando-lhe: "quando passares pelo rio Jordão e perguntares o que levas, responde "levo o cordão de São Francisco, três pingos de vela benta e a Virgem da Conceição'". Após a morte, dá-se dez nós em um cordão de mais ou menos um centímetro de diâmetro, passado em volta da cintura do morto, rezando uma avemaria para cada nó, encerrando com um pai-nosso. Em outras palavras, o morto não navega sem rumo pelo espaço; vem "amarrado" por um fio que o manterá em contato com outras dimensões, o que vem ao encontro das concepções de Eliade $(1998 ; 1996)$ sobre a sobrevivência dos "refugos" mitológicos e imaginários, mesmo nas sociedades modernas.

\section{TORNAR TRANSPARENTE ...PARA UMA PRÁTICA MAIS ENRIQUECIDA}

Uma vez que o símbolo "fala" de uma realidade ou situação existencial humana e confere significado a essa existência, possibilita ao ser humano sair de sua subjetividade e reconhecer a objetividade de suas experiências pessoais, "abrindo-se" à compreensão do universal e transcendendo a própria condição humana.

Se queremos prestar um cuidado integral - a tão almejada assistência holística, este precisa ser significante para quem cuida e para quem é cuidado. Deve, portanto, ser simbólico e não apenas técnico (ainda que na aparência, já que há um simbolismo mesmo que camuflado, empobrecido), estabelecendo uma conexão com todas as dimensões humanas e cósmicas.

"Enxergar" o simbolismo enriquece a imaginação. Na prática de enfermagem, isto permite a ruptura da crença equivocada de que alguns procedimentos de enfermagem pertencem a uma dimensão meramente técnica . Então, a imaginaçăo de cuidadoras e cuidadores enriquecida pelo simbolismo beneficia uma prática criativa, sensivel, sensual, prazerosa e produtora de subjetividade compartilhada com o sujeito do cuidado.

ABSTRACT: This study establishes analogies between some universal symbols and death rituals developed in nursing, based on the comprehension of ELIADE. It shows the existent camouflage of these rituals in the nursing profession and points out to the need of eliciting (making transparent) these practices in order to enrich nursing practice, thus benefitting caretakers and patients.

KEYWORDS: symbolism, nursing, death rituals.

RESUMEN: El ensayo establece, a partir de la comprensión de Eliade, semajanzas entre algunos símbolos universales y los rituales de muerte desarrollados por la enfermeria, desnudando el camuflaje alli existente y apuntando su transparencia como forma de enriquecer la práctica profesional y beneficiar a cuidadora(e)s y a sujetos del cuidado.

PALABRAS CLAVE: simbolismo, enfermeria, rituales de muerte

\section{BIBLIOGRAFIA}

ATKINSON, L. D.; MURRAY, M. G. Fundamentos de enfermagem. Rio de Janeiro: Guanabara-Koogan, 1989 
ELIADE, M. Imagens e simbolos. São Paulo: Martins Fontes, 1996. . Mefistófeles e o andrógino. São Paulo: Martins Fontes, 1991. Tratado de história das religiōes. São Paulo: Martins Fontes, 1998. O sagrado $\theta$ o profano. São Paulo: Martins Fontes, 1999.

FIGUEIREDO, N.M. A ; CARVALHO, V. Na teia do cuidar os delicados "nós" do cuidado - a enfermagem diurna e a enfermagem noturna. In: CONGRESSO BRASILEIRO DE ENFERMAGEM, 50., 1998, Salvador. Anais... Salvador: ABEn Nacional, 1998.

MAMEDE, M.V.; CARVALHO, E.C.; CUNHA, A. M. P. Técnicas em enfermagem. São Paulo: Sarvier, 1984.

MIRANDA, C.L. O risco e o bordado. São Paulo: Cortez, 1998.

REIS, J.J. A morte é uma festa. São Paulo: Companhia das Letras, 1995.

RIBEIRO, M.C. et al. A percepção da equipe de enfermagem em situação de morte; ritual do preparo do corpo "pós-morte". Rev. ESc. USP, São Paulo, v. 32, n.2, p. 117-23, ago. 1998.

SILVEIRA, M.F.A.; MANTOVANI, M.F; CADE, N.V. Os nós que atam a autonomia na enfermagem. CONGRESSO BRASILEIRO DE ENFERMAGEM, 50., 1998, Salvador. Resumos... Salvador: ABEn Nacional, 1998.

STYLES, M.M. Nithingale : the enduring symbol. In: NIGHTINGALE, F. Notes on nursing. Philadelphia: J.B.Lippincot Company, 1992. 